\title{
Impact of Mobile Assisted Language Learning (MALL) on EFL: A Meta-Analysis
}

\author{
Imtiaz Hassan Taj (Corresponding author) \\ PO Box 110324, University of Jeddah, Jeddah 21361 \\ Kingdom of Saudi Arabia \\ E-mail: imtiaz468ht@gmail.com \\ Norrihan Binti Sulan \\ Center for Modern Languages and Human Sciences, \\ Universiti Malaysia Pahang, \\ Lebuhraya Tun Razak, Pahang 26300, Malaysia \\ E-mail: norrihan@ump.edu.my \\ Muhammad Aslam Sipra \\ PO Box 80283, King Abdulaziz University Jeddah 21589 \\ Kingdom of Saudi Arabia \\ E-mail:makhan6@kau.edu.sa \\ Waqar Ahmad \\ PO Box: 110345, University of Jeddah, Jeddah 21361 \\ Kingdom of Saudi Arabia \\ E-mail:waqar22@gmail.com
}

Doi:10.7575/aiac.alls.v.7n.2p.76

URL: http://dx.doi.org/10.7575/aiac.alls.v.7n.2p.76
Received: 06/11/2015

Accepted: 17/01/2016

\begin{abstract}
Mobile Assisted Language Learning (MALL) has emerged as a potential tool in the instruction of English as a foreign language (EFL). Meta-analysis of 13 studies published between year 2008 and 2015 was conducted. Four point criteria for the selection of studies for analysis is based on the year of publication, quasi-experimental design, pretest and posttest method and finally use of mobile device for intervention. Findings of the analysis suggest that MALL has fostered the EFL instruction. Overall effect size was $(d=0.8)$ which is considered a large effect size.
\end{abstract}

Keywords: MALL, technology assisted language learning, EFL, vocabulary acquisition, vocabulary instruction, metaanalysis

\section{Introduction}

We live in a world now so obsessed with speed (Devine, 2014). In fact speed is one the most defining ideals of our lives. Speed is further propelled by technological innovations in the field of telecommunications. It has reached mind boggling limits of 1tbs/s (Hecht, 2004). The web has registered a phenomenal growth of $806 \%$ over the past fifteen years with more than 3.2 billion users (http://www.internetworldstats.com/stats.htm). Mobile phones are used by over two billion users. An average American is glued to electronic screen for about 56\% of a workday (http://www.smartinsights.com/mobile-marketing/). Ubiquitous nature of this connectivity has drawn the interest of educators worldwide. In this regard, language studies are of particular beneficiaries. Since use of language is free of time and place constraints, it stands to reason that its instruction may also be free of such constraints. Mobile phones offer such an opportunity where language can be learnt anywhere and anytime.

\section{Literature Review}

Mobile phones have recorded a tremendous growth since Chickering and Ehrmann (1996) coined the term MALL (Mobile Assisted Language Learning). More recently, the term has been associated with mobile phones. These phones with user friendly interfaces, ubiquitous access and improved data storage and retrieval capacities offer a good platform for learning (Gabarre, Gabarre, Din, Shah, \& Karim, 2014; Godwin-Jones, 2011; Miangah \& Nezarat, 2012). Insights from CALL (Computer Assisted Language Learning) can be used to inform the learning activities presented through mobile phones (Kukulska-Hulme, 2005). Because these phones are miniature form of PCs with additional benefit of portability which surpasses laptop computers. This leap of technology from lap to palm has literally given a potential language learning tool in the hands of the teachers and their students (Kukulska-Hulme, 2009). Our lives are deeply immersed in technology. Same view was held by a majority of participants (Huw Jarvis \& Achilleos, 2013). Mobile 
phones can deliver interesting, engaging and motivating learning activities. Learners like these affordances of mobile technology where they can connect with their peers to complete learning activities (Palalas, 2011). Completing learning tasks collaboratively through mobile phones was found effective (Lan, Sung, \& Chang, 2007; Lim Abdullah, Hussin, Asra, \& Zakaria, 2013). From the standpoint of transactional distance, also mobile phones have an advantage. The instructors can initiate the learners into a learning environment where they provide initial scaffolding and then gradually withdraw the support to allow learners take charge of their learning (Park, 2011). MALL fits well into PPP (Presentation, practice and production paradigm). Mobile phones can present rich learning material in multimodal ways (HA Jarvis, 2015; Mayer, 2003). Evaluation of six pilot projects in developing countries (Valk, Rashid, \& Elder, 2010) concluded that mobile phones have the potential to impart instruction. They have the potential to help create an environment that is conducive for a variety of learning scenarios such as formal and informal learning (Lung-Hsiang Wong, 2012).

SMS is considered the ace application in the mobile industry. Over 150 billion text messages were sent in the UK alone in 2011 (https://www.textmarketer.co.uk). It seems to be the most frequently used option in imparting language instruction as well. In many studies, it was employed and positive results were reported on its efficacy (Alavinia \& Qoitassi, 2013; Chen, Hsieh, \& Kinshuk, 2008; Motallebzadeh \& Ganjali, 2011; Yang, 2013). In addition, the skill area of the choice seems to be vocabulary acquisition (Duman, Orhon, \& Gedik, 2015; H.-S. Kim, 2011; H. Kim \& Kwon, 2012).

Teachers and students alike have embraced the idea of mobile learning with a lot of enthusiasm. The salient popular feature of such learning are mobility and ubiquitous access. The teachers liked the idea as it gives them a lot of options to present instructional material in interesting ways $(\mathrm{Oz}, 2015)$. The students also like the idea of mobile learning because of its mobility feature, the convenience it affords in terms of time management and the option to engage in group work (Anaraki, 2009; Deng \& Shao, 2011; Tai, 2012; L-H Wong \& Looi, 2010). The design of MALL tasks needs special attention. The tasks should be user friendly, sensitive to the social and cultural setting and engaging and short. Built around these guidelines, the MALL tasks have a lot of potential for learning (Stockwell \& Hubbard, 2013).

\section{MAMALL}

Initially, 15 studies were selected for the meta-analysis but two studies were dropped because of highly inconsistent results. The meta-analysis was undertaken to shed light on the lessons learnt through research so far. The need for this kind of analysis was felt by Glass (1976). There is a growing body of evidence being accumulated in research articles individually, which has given rise to the need that this evidence may be collected and informed analysis is conducted of what has already been learnt. MALL is relatively young field, which can benefit from the type of inquiry undertaken in this meta-analysis. A collection of annotated bibliography (Burston, 2013) brought forth interesting information. Bulk of research on MALL has been published in diverse type of journals while only $10 \%$ research is reported in CALL journals. Absence of a MALL dedicated journal makes the meta-analysis studies more beneficial.

\section{Hypotheses and Objectives}

The meta-analysis sought to answer the following research questions.

1. How effective is Mobile Assisted Language Learning in teaching EFL?

2. Is Mobile Assisted Language Learning effective for certain age group of learners?

The studies reviewed in the literature review point to the efficacy of Mobile Assisted Language Learning in teaching EFL. It is also evident that the area of choice so far is vocabulary acquisition. Almost all the studies consistently produced positive results. The participants seem to benefit from this new platform. An effort was made in this metaanalysis to collect quantifiable information from the studies included in the analysis to glean knowledge from the information dispersed in these studies (Glass, 1976). Majority of MALL studies out of 54 (Viberg \& Grönlund, 2012) had no mention of theory. Experiment was found to be the favoured method. The experimental methods are favoured because they are better than no experiment at all (Cooper, Hedges, \& Valentine, 2009).

\section{Methodology}

This section describes the methodology used in this meta-analysis. It also discusses the methods through which studies were searched and retrieved.

\subsection{Literature Search}

Literature search was conducted using different databases including ERIC, digital libraries of University of Jeddah, Universiti Malaysia Pahang and Google Scholar. There were 25 MALL studies collected through these searches. Out of these, 13 were used in this meta-analysis. Others were rejected as they did not match the criteria as described below:

\subsection{Criteria}

The following criteria for inclusion were set:

a. The study was published between 2008 and 2015 .

b. The study used quasi-experimental method.

c. The study report or part of it had pretest, posttest design with a control group.

d. The study used mobile device or devices for intervention

Thirteen studies satisfied the above-mentioned criteria and were included in the meta-analysis. 


\section{Study Characteristics}

Following study characteristics were studied:
a. Sampling procedure
b. Sample size
c. Participants grade level
d. Target language area
e. Duration of treatment
f. Type of instrument used (standardized vs researcher made)
g. Type of application used for treatment

The above-mentioned characteristics of the studies in the meta-analysis were tabulated. As presented in the tables below, most of the studies about $31 \%$ reported here were published in year 2011(table.1). Iran topped the list in the countries where these studies were originated. About 38.5\% studies were done in Iran followed by China and Korea about $15.5 \%$ each. Conspicuously, no study from an Anglophonic country was reported (table.2). Majority of studies used researcher made or non-standardized instruments for data collection about $61.5 \%$ while about $38.5 \%$ studies used standardized instruments (table.3). All studies in this meta-analysis except one that used PDA (Personal Digital Assistant) used mobile phones as platform on which content was delivered (table.4). Application of choice for learning content delivery was SMS about $65.5 \%$ followed by dedicated applications about 30.8\% (table.5). Sample size of about $54 \%$ studies was between 30 to 50 subjects. One study had sample size between 100 to 200 subjects (table.6). Majority of studies $84.5 \%$ had treatment duration of between 1 to 10 weeks. Only one study which $7.7 \%$ of the studies included in the meta-analysis had a treatment period of six months (table.7). Majority of the subjects about $54 \%$ in these studies were sophomore students. They were in their first or second year at the universities. Only one study $7.7 \%$ had fifth grader subjects (table.8). Target language area in about $93 \%$ of the studies was vocabulary. Only one study targeted grammar (table.9).

Table 1. Year of Publication

\begin{tabular}{ccc}
\hline Year & Number & Percentage \\
\hline 2008 & 1 & 07.7 \\
2010 & 3 & 23 \\
2011 & 4 & 30.7 \\
2012 & 2 & 15.3 \\
2013 & 1 & 07.7 \\
2015 & 2 & 15.3 \\
\hline Total & $\mathbf{1 3}$ & $\mathbf{1 0 0}$ \\
\hline
\end{tabular}

Table 2. Studies by Country of Origin

\begin{tabular}{ccc}
\hline Year & Number & Percentage \\
\hline Korea & 1 & 07.7 \\
Netherlands & 1 & 07.7 \\
Thailand & 1 & 07.7 \\
Turkey & 1 & 07.7 \\
Taiwan & 2 & 15.38 \\
China & 2 & 15.38 \\
Iran & 5 & 38.46 \\
\hline Total & $\mathbf{1 3}$ & $\mathbf{1 0 0}$ \\
\hline
\end{tabular}

Table 3. Type of Instrument Used for Data Collection

\begin{tabular}{ccc}
\hline Instrument & Number & Percentage \\
\hline Standardized & 5 & 38.46 \\
Non-standardized & 8 & 61.53 \\
\hline Total & $\mathbf{1 3}$ & $\mathbf{1 0 0}$ \\
\hline
\end{tabular}


Table 4. Platform Used for Content Delivery

\begin{tabular}{ccc}
\hline Platform & Number & Percentage \\
\hline Mobile Phone & 12 & 92.3 \\
PDA & 1 & 7.7 \\
\hline Total & $\mathbf{1 3}$ & $\mathbf{1 0 0}$ \\
\hline
\end{tabular}

Table 5. Application Used for Content Delivery

\begin{tabular}{ccc}
\hline Platform & Number & Percentage \\
\hline SMS & 8 & 61.54 \\
Special Application & 4 & 30.77 \\
Unknown & 1 & 7.7 \\
\hline Total & $\mathbf{1 3}$ & $\mathbf{1 0 0}$ \\
\hline
\end{tabular}

Table 6. Statement of Sample Sizes

\begin{tabular}{ccc}
\hline Year & Number of studies & Percentage \\
\hline $30-49$ & 7 & 53.9 \\
$50-100$ & 5 & 38.47 \\
$100-200$ & 1 & 7.7 \\
\hline Total & $\mathbf{1 3}$ & $\mathbf{1 0 0}$
\end{tabular}

Table 7. Treatment Duration of the Studies

\begin{tabular}{ccc}
\hline Weeks & Number & Percentage \\
\hline $1-10$ & 11 & 84.61 \\
$11-20$ & 1 & 7.7 \\
$21-30$ & 1 & 7.7 \\
\hline Total & $\mathbf{1 3}$ & $\mathbf{1 0 0}$
\end{tabular}

Table 8. Grade Levels of Participants

\begin{tabular}{ccc}
\hline Grade Level & Number & Percentage \\
\hline K-5 & 1 & 07.7 \\
K-10 & 2 & 15.38 \\
K-12 & 1 & 07.7 \\
Sophomore & 7 & 53.9 \\
Undergraduate & 1 & 07.7 \\
\hline Total & $\mathbf{1 3}$ & $\mathbf{1 0 0}$ \\
\hline
\end{tabular}

Table 9. Targeted Language Area

\begin{tabular}{ccc}
\hline Skill & Number & Percentage \\
\hline Vocabulary & 12 & 92.3 \\
Grammar & 1 & 7.7 \\
\hline Total & $\mathbf{1 3}$ & $\mathbf{1 0 0}$ \\
\hline
\end{tabular}

\section{Effect Sizes}

Effect size refers to the magnitude of effect made by the treatment. It has been identified as an important measure in evaluating research outcomes (Cohen, 1992; Cooper et al., 2009; Kline \& Association, 2004). It is scale free measure 
originally proposed for research in psychology and is used in other social sciences such as language studies. Importance of effect sizes multiplied with the advent of meta-analysis in late 70s (Glass, 1976) and more recently with growing dissatisfaction with statistical testing of the hypotheses (Kline \& Association, 2004). Scary possibility of getting every result significant if a large enough sample size could be employed (Thompsons \& Snyder, 1998), has brought some researchers to the point that they have started advocating a ban on statistical testing. There is growing pressure on researchers to report effect sizes in their research reports.

Calculation of effect sizes is not as straight forward as it sometimes looks at the surface. There are two competing approaches to calculate effect size of a study or of studies for the purpose of meta-analysis. One approach is to calculate it as $d$ commonly known as Cohen's $d$ which is calculated on the basis of mean scores of the treatment and control groups and pooled standard deviation. Cohen (1992) provided some guiding scale in which $.2, .5$ and .8 are suggested as small, medium and large sizes respectively. There are two more variations of this approach in form of Hedge's $g$ and Glass's $\square$ which are basically slight improvements of $d$ calculations (Turner \& Bernard, 2006). Second approach is called $r$ type effect size. This approach calculate effect size through t value and degrees of freedom. To satisfy one of its assumptions of normal distribution $r$ is transformed into Fisher's z (Kline \& Association, 2004; Rosenthal, 1991).

In the present meta-analysis, the $d$ type effect sizes were calculated first for each study along with Hedge's $g$ with the help of a calculator downloaded from http://www.stat-help.com/. In the second step, $r$ type effect sizes were calculated through a calculator downloaded from http://www.uccs.edu/ lbecker/. These effect sizes were transformed into Fisher's $\mathrm{Z}$ to satisfy normal distribution assumption through the following formula:

$$
Z_{Y}=\frac{1}{2} \log _{e}\left[\frac{1+r}{1-r}\right]
$$

$\mathrm{Z}_{\mathrm{r}}$ scores were then multiplied by ( $\left.\mathrm{n}-3\right)$ to get weighted effect sizes accommodating sample sizes (table. 10). Overall $\mathrm{Z}_{\mathrm{r}}$ and standard error were calculated through the following formulas:

$$
\begin{gathered}
Z_{Y}=\frac{\sum(n-a) z_{Y}}{\sum(n-a)} \\
\text { Standard Error }=\sqrt{\frac{1}{\sum(n-a)}}
\end{gathered}
$$

\begin{tabular}{|c|c|c|c|c|}
\hline No. & The Study & Sample n & $\begin{array}{c}\text { Effect Size } \\
Z_{r}\end{array}$ & $\begin{array}{c}\text { Weighted E.S. } \\
(n-3) Z_{r}\end{array}$ \\
\hline 1 & Wu, Q. (2015) & 199 & 0.43 & 40.38 \\
\hline 2 & Derakhshan, A., \& Kaivanpanah, S. (2011) & 43 & 0.30 & 5.79 \\
\hline 3 & Sandberg, J., Maris, M., \& de Geus, K. (2011) & 51 & 0.59 & 14.16 \\
\hline 4 & Chen, C.-M., \& Li, Y.-L. (2010) & 36 & 0.11 & 1.70 \\
\hline 5 & Kim, H.-S. (2011) & 42 & 0.63 & 11.37 \\
\hline 6 & Azabdaftari, B., \& Mozaheb, M. (2012) & 80 & 0.61 & 22.61 \\
\hline 7 & Basoglu, E. B., \& Akdemir, O. (2010) & 58 & 0.09 & 2.24 \\
\hline 8 & Suwantarathip, O., \& Orawiwatnakul, W. (2015) & 80 & 0.31 & 11.50 \\
\hline 9 & Baleghizadeh, S., \& Oladrostam, E. (2010) & 40 & 0.55 & 9.42 \\
\hline 10 & Zhang, H., Song, W., \& Burston, J. (2011) & 64 & 0.30 & 8.23 \\
\hline 11 & Hayati, A., Jalilifar, A., \& Mashhadi, A. (2013) & 45 & 0.80 & 21.71 \\
\hline 12 & Alemi, M., Sarab, M. R. A., \& Lari, Z. (2012) & 45 & 0.23 & 3.21 \\
\hline 13 & Lu, M. (2008) & 30 & 0.34 & 4.14 \\
\hline
\end{tabular}

Table 10. Effect Sizes of the Studies

\section{Results and Discussion}

In this section the results of the analysis are presented. As shown in the table 11 below, the overall effect size was 0.425 $(E S=0.425)$ which is markedly different from 0 as $Z$ combined was found to be 8.156 which is greater than 1.96 for $\alpha=$ 0.05 in standard normal distribution. Standard error was calculated as 0.0521 ( $S E=0.0521$ ). Lower and upper limits for $95 \%$ confidence interval were found to be 0.323 and 0.527 respectively. 
Table 11. Results of the Meta-analysis

\begin{tabular}{lcccc}
\hline Effect size & Z Combined & Standard Error & \multicolumn{2}{c}{ Confidence Interval 95 \% } \\
\hline & & & Lower Limit & Upper Limit \\
0.425 & 8.156 & 0.0521 & 0.323 & 0.527 \\
\hline
\end{tabular}

MALL has come a longway since Chinnery ( 2006) used the term first time. Over all results of the present metaanalysis suggest that intervention through mobile phones helps in EFL learning. Similar results have been reported in (Lim Abdullah et al., 2013; Miangah \& Nezarat, 2012). Research in the field of MALL seems to be in disarray as there seems to be no dedicated journal for MALL studies. Bulk of literature comes from conference proceedinds (Burston, 2014). As evident from present meta-analysis, major focus of the research is vocabulary acquisition (Chu, 2011; Duman et al., 2015; H. Kim \& Kwon, 2012). In view of the critical importance of vocabulary especially in EFL settings MALL is emerging an important tool for vocabulary instruction. Present study seems to confirm the view that mobile phones with their increasing capabilities to provide connectivity in a ubiquitous environment can be used as effective tools for delivering lnguage learning content. As in this study and elsewhere (H. Kim \& Kwon, 2012; Motallebzadeh \& Ganjali, 2011) as well it is found that MALL activities have been mostly directed at sophomore students. As for as the second research question regarding age of the learners is concerned there was no pattern discovered to indicate that MALL intervention is useful only for certain age group. It has been found effective with learners irrespective of their age. However keeping in view the number of studies included in this meta-analysis $(N=13)$, the findings may be interpreted more cautiously.

Staticians believe that a publication bias might exist because of which studies that do not have significant results are not published. This is commonly referred to as "The File Drawer" problem. As for as the present meta-analysis is conecrned, the number of studies which could have existed but were not published because of this bias is calculated through the following formula by Rosenthal (1991):

$$
x=\frac{C z p^{2}}{2.306}-R
$$

According to the calculations 51 studies are needed to reverse the findings of this meta-analysis.

As shown in the figures below, there was no corelation visible between either the grade level and effect sizes (figure.1) or between the sample size and effect sizes (figure.2). it can be concluded that effect of MALL seems independent of grade level and sample size.

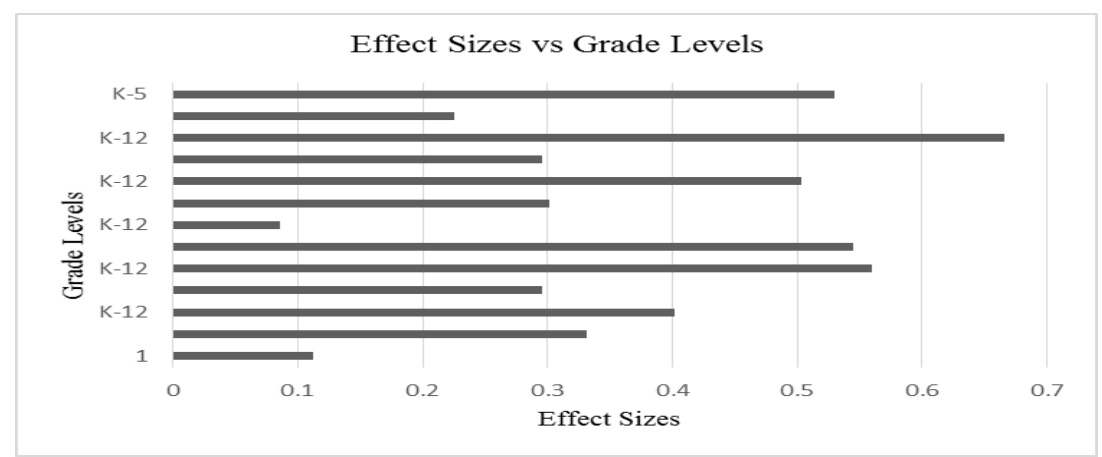

Figure 1. Effect Sizes vs Grade Levels

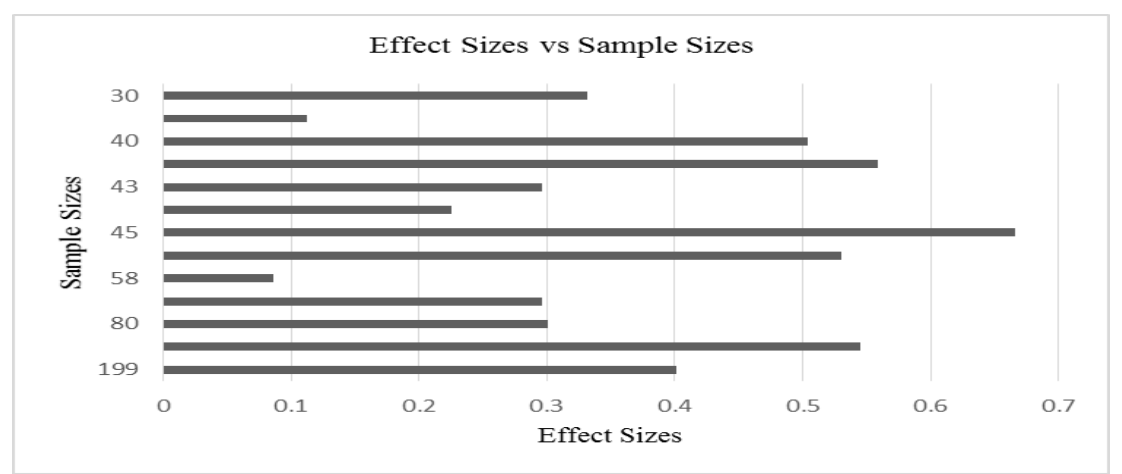

Figure 2. Effect Sizes vs Sample Sizes

\section{Limitations}

The present meta-analysis like all other inquiries in social science has some limitations. Firstly, the number of studies included in the analysis was very small. MALL is relatively a young field only a couple of decades have passed since its 
beginning in mid-90s. That is one reason for the shortage of studies. Another reason may be absence of a dedicated journal for MALL. Secondly, only studies reporting mean scores and standard deviations for control and treatment groups were included.

\section{Conclusion}

Mobile Assisted Language Learning has emerged as a potential assistive tool in the complex process of language learning. Technological advances in the last quarter of the last century have made it mandatory for the teachers to employ technology as a tool to help in the process of teaching and learning. The present meta-analysis was conducted to synthesize the lesson learnt so far in the field of MALL. The findings confirm the efficacy of the platform of MALL in EFL instruction.

\section{References}

Alavinia, P., \& Qoitassi, K. (2013). On the viability of vocabulary learning enhancement through the implementation of MALL: The case of Iranian EFL learners. Journal of Language Teaching and Research, 4(2), 412-426.

Anaraki, F. B. (2009). A flash-based mobile learning system for learning English as second language. Paper presented at the ICCET '09 Proceedings of the 2009 International Conference on Computer Engineering and Technology, Singapore, IEEE, 400-404.

Burston, J. (2013). Mobile-assisted language learning: A selected annotated bibliography of implementation studies 1994-2012. Language Learning \& Technology, 17(3), 157-224.

Burston, J. (2014). The Reality of MALL: Still on the Fringes. CALICO Journal, 31(1), 103.

Chen, N.-S., Hsieh, S.-W., \& Kinshuk, A. (2008). Effects of short-term memory and content representation type on mobile language learning. Language Learning \& Technology, 12(3), 93-113.

Chickering, A. W., \& Ehrmann, S. C. (1996). Implementing the seven principles: Technology as lever. AAHE Bulletin, 49, 3-6.

Chinnery, G. M. (2006). Emerging Technologies: Going to the MALL (Mobile Assisted Language Learning). Language Learning \& Technology, 10(1), 9-16.

Chu, H. (2011). The effect of the features of smart phone vocabulary applications on Korean college students' satisfaction and continued use. Multimedia Assisted Language Learning, 14(2), 91-112.

Cohen, J. (1992). A power primer. Psychological Bulletin, 112(1), 155-159.

Cooper, H., Hedges, L. V., \& Valentine, J. C. (2009). The handbook of research synthesis and meta-analysis: Russell Sage Foundation.

Deng, H., \& Shao, Y. (2011). Self-directed English vocabulary learning with a mobile application in everyday context. Paper presented at the 10th World Conference on Mobile and Contextual Learning: mLearn 2011 Conference Proceedings, Beijing, China. mLearn, 24-31.

Devine, A. (2014). Colour Coding for Learners with Autism: A Resource Bookfor Creating Meaning through Colour at Home and School: Jessica Kingsley Publishers.

Duman, G., Orhon, G., \& Gedik, N. (2015). Research trends in mobile assisted language learning from 2000 to 2012. ReCALL, 27(02), 197-216.

Gabarre, C., Gabarre, S., Din, R., Shah, P. M., \& Karim, A. A. (2014). iPads in the foreign language classroom: A learner's perspective. Southeast Asian Journal of English Language Studies, 20(1), 115-127.

Glass, G. V. (1976). Primary, secondary, and meta-analysis of research. Educational researcher, 3-8.

Godwin-Jones, R. (2011). Emerging technologies: Mobile apps for language learning. Language Learning \& Technology, 15(2), 2-11.

Hecht, J. (2004). City of light: the story of fiber optics. New York: Oxford university press.

Jarvis, H. (2015). From PPP and CALL/MALL to a praxis of task-based teaching and mobile assisted language use. Teaching English as a Second or Foreign Language Electronic Journal, 19(1), 1-10.

Jarvis, H., \& Achilleos, M. (2013). From Computer Assisted Language Learning (CALL) to Mobile Assisted Language Use (MALU). TESL-EJ, 16(4), 1-18.

Kim, H.-S. (2011). Effects of SMS text messaging on vocabulary learning. Multimedia Assisted Language Learning, $14(2), 159-180$.

Kim, H., \& Kwon, Y. (2012). Exploring smartphone applications for effective mobile-assisted language learning. Multimedia-Assisted Language Learning, 15(1), 31-57.

Kline, R. B., \& Association, A. P. (2004). Beyond significance testing: Reforming data analysis methods in behavioral research. Washington, DC 20002: American Psychological Association.

Kukulska-Hulme, A. (2005). Mobile learning: A handbook for educators and trainers. New York, NY 10016: Routledge.

Kukulska-Hulme, A. (2009). Will mobile learning change language learning? ReCALL, 21(02), 157-165.

Lan, Y.-J., Sung, Y.-T., \& Chang, K.-E. (2007). A mobile-device-supported peer-assisted learning system for collaborative early EFL reading. Language Learning \& Technology, 11(3), 130-151.

Lim Abdullah, M., Hussin, Z., Asra, B., \& Zakaria, A. R. (2013). MLearning scaffolding model for undergraduate English language learning: bridging formal and informal learning. TOJET: The Turkish Online Journal of Educational Technology, 12(2), 217-233.

Mayer, R. E. (2003). The promise of multimedia learning: using the same instructional design methods across different media. Learning and instruction, 13(2), 125-139.

Miangah, T. M., \& Nezarat, A. (2012). Mobile-assisted language learning. International Journal of Distributed and Parallel Systems, 3(1), 309-319. 
Motallebzadeh, K., \& Ganjali, R. (2011). SMS: Tool for L2 vocabulary retention and reading comprehension ability. Journal of Language Teaching and Research, 2(5), 1111-1115.

Oz, H. (2015). An Investigation of Preservice English Teachers' Perceptions of Mobile Assisted Language Learning. English Language Teaching, 8(2), 22-35.

Palalas, A. (2011). Mobile-assisted language learning: Designing for your students. In S. Thouësny \& L. Bradley (Eds.), Second language teaching and learning with technology: Views of emergent researchers. Dublin, Ireland: Researchpublishing.net.

Park, Y. (2011). A pedagogical framework for mobile learning: Categorizing educational applications of mobile technologies into four types. The International Review of Research in Open and Distributed Learning, 12(2), 78-102.

Rosenthal, R. (1991). Meta-analytic procedures for social research. In L. Bickman \& D. J. Rog (Eds.), Applied Social Research Methods Series (Vol. 6). Newbury Park, California 91320: SAGE Publications, Inc.

Stockwell, G., \& Hubbard, P. (2013). Some emerging principles for mobile-assisted language learning. The International Research Foundation for English Language Education. Retrieved from http://www.tirfonline.org/englishin-the-workforce/mobile-assisted-language-learning

Tai, Y. (2012). Contextualizing a MALL: Practice design and evaluation. Journal of Educational Technology \& Society, 15(2), 220-230.

Thompsons, B., \& Snyder, P. A. (1998). Statistical significance and reliability analyses in recent Journal of Counseling \& Development research articles. Journal of Counseling \& Development, 76(4), 436-441.

Turner, H. M., \& Bernard, R. M. (2006). Calculating and synthesizing effect sizes. Contemporary issues in communication science and disorders, 33, 42-55.

Valk, J.-H., Rashid, A. T., \& Elder, L. (2010). Using mobile phones to improve educational outcomes: An analysis of evidence from Asia. The International Review of Research in Open and Distributed Learning, 11(1), 117-140.

Viberg, O., \& Grönlund, A. (2012). Mobile assisted language learning: A literature review. Paper presented at the 11th World Conference on Mobile and Contextual Learning, Helsinki, Finland. mLearn 2012. 1-8.

Wong, L. H. (2012). A learner-centric view of mobile seamless learning. British Journal of Educational Technology, 43(1), E19-E23.

Wong, L. H., \& Looi, C. K. (2010). Vocabulary learning by mobile-assisted authentic content creation and social meaning-making: two case studies. Journal of Computer Assisted Learning, 26(5), 421-433.

Yang, J. (2013). Mobile assisted language learning: review of the recent applications of emerging mobile technologies. English Language Teaching, 6(7), 19-25.

\section{Appendix}

(List of Studies)

1. Alemi, M., Sarab, M. R. A., \& Lari, Z. (2012). Successful learning of academic word list via MALL: Mobile assisted language learning. International Education Studies, 5(6), p99.

2. Azabdaftari, B., \& Mozaheb, M. (2012). Comparing vocabulary learning of EFL learners by using two different strategies: mobile learning vs. flashcards. The EUROCALL Review, 20(2), 47-59.

3. Baleghizadeh, S., \& Oladrostam, E. (2010). The effect of mobile assisted language learning (MALL) on grammatical accuracy of EFL students. MEXTESOL Journal, 34(2), 1-10.

4. Basoglu, E. B., \& Akdemir, O. (2010). A Comparison of Undergraduate Students' English Vocabulary Learning: Using Mobile Phones and Flash Cards. Turkish Online Journal of Educational Technology-TOJET, 9(3), 1-7.

5. Chen, C.-M., \& Li, Y.-L. (2010). Personalised context-aware ubiquitous learning system for supporting effective English vocabulary learning. Interactive Learning Environments, 18(4), 341-364.

6. Derakhshan, A., \& Kaivanpanah, S. (2011). The Impact of text-messaging on EFL freshmen's vocabulary learning. European Association for Computer Assisted Language Learning, 39.

7. Hayati, A., Jalilifar, A., \& Mashhadi, A. (2013). Using Short Message Service (SMS) to teach English idioms to EFL students. British Journal of Educational Technology, 44(1), 66-81.

8. Kim, H.-S. (2011). Effects of SMS text messaging on vocabulary learning. Multimedia Assisted Language Learning, 14(2), 159-180.

9. Lu, M. (2008). Effectiveness of vocabulary learning via mobile phone. Journal of computer assisted learning, 24(6), 515-525.

10. Sandberg, J., Maris, M., \& de Geus, K. (2011). Mobile English learning: An evidence-based study with fifth graders. Computers \& Education, 57(1), 1334-1347.

11. Suwantarathip, O., \& Orawiwatnakul, W. (2015). Using Mobile-Assisted Exercises to Support Students'Vocabulary Skill Development. Turkish Online Journal of Educational Technology, 14(1), 163.

12. Wu, Q. (2015). Pulling Mobile Assisted Language Learning (MALL) into the Mainstream: MALL in Broad Practice. PloS one, 10(5), e0128762-e0128762.

13. Zhang, H., Song, W., \& Burston, J. (2011). Reexamining the effectiveness of vocabulary learning via mobile phones. The Turkish Online Journal of Educational Technology 10 (3), 203-214 (2011). 